\title{
A strategic approach to the design and implementation of an effective mine dewatering system
}

\author{
M. Bester Anglo American Kumba Iron Ore, South Africa \\ E. Nel Anglo American Kumba Iron Ore, South Africa
}

G.M. Mc Gavigan Anglo American Kumba Iron Ore, South Africa

\begin{abstract}
In order to reduce business and safety risk at Anglo American Kumba Iron Ore mining operations, it is imperative that groundwater is strategically managed to ensure dry mining conditions and depressurised slopes whilst ensuring maximum effective usage of the abstracted water and managing the potential environmental impacts. Hydrogeological input into slope design is required in order to ensure safe mine production and minimisation of costs. A structured approach according to engineering design principles is suggested for the design and implementation of an effective and efficient mine dewatering system. Comprehensive data collection and site characterisation, conceptual and numerical groundwater flow modelling as well as dewatering simulations are required to accurately determine the dewatering system requirements. Subsequent to implementation, a comprehensive monitoring program is put in place in order to optimise the dewatering system and effectively manage the environmental impact. The implementation phase of an effective dewatering strategy at Sishen and Kolomela Mines are discussed as case studies.
\end{abstract}

\section{Introduction}

The design of an effective dewatering system involves the consideration of a variety of factors. Due to the uniqueness of each site, comprehensive data collection and characterisation, modelling, and analysis are required to predict the dewatering requirements. A design must be implemented that will satisfy all technical requirements whilst also meeting objectives in terms of legal and environmental aspects, water usage and discharge whilst considering the financial implications of the various options.

According to Stacey (2009) a satisfactory design is fundamental to the expected performance of any system and the key inputs into a design are needed during the early stages of a project when the most important decisions are made. These decisions (or inputs) will form the basis of the requirements for the design.

The complexities involved in mine dewatering systems employed by Anglo American Kumba Iron Ore operations, requires a structured methodology to design and implement an effective and efficient system that best satisfies all objectives.

The bulk of Anglo American Kumba Iron Ore's production comes from Sishen Mine, located in South Africa's Northern Cape Province near the mining town of Kathu. Opened in 1947, Sishen Mine is Kumba's flagship operation and one of the seven largest open pit mines in the world. It operates $24 / 7$ and has a capacity of approximately 40 million tonnes (Mtpa) of iron ore and a life-of-mine of 21 years.

Most of Sishen mine's iron ore is exported to clients around the world (Figure 1). All mining is done by open-cast methods, with ore transported to the beneficiation plant where it is crushed, screened and beneficiated. Sishen is the only haematite ore producer in the world to fully beneficiate its product, made possible through dense medium separation (DMS) and jig technology. The Jig Plant at Sishen Mine is the largest of its type in the world. Iron ore products, conforming to different chemical and physical specifications, are produced at this mine. 
Water abstracted from the mine is used for mining operations and the daily requirements of the town Kathu that houses Sishen's employees. The balance is exported to other mines and towns in the area.

Kolomela Mine is one of Anglo American's Big Four expansion projects alongside Barro Alto in Brazil (nickel), Minas Rio in Brazil (ferrous) and Los Bronces in Chile (copper). The mine is situated in the town of Postmasburg approximately $100 \mathrm{~km}$ south of Kathu in the Northern Cape Province, South Africa. The project was completed on time, on budget, with Zero Harm at the end of 2011. The mine is on schedule for full capacity of 9 Mtpa of direct-shipping ore for export in 2013 with a life-of-mine of 28 years.

Similar to Sishen Mine, water abstracted from Kolomela Mine is utilised for mining operations while the balance is exported to the regional water management authority.

\section{Design principles}

According to Stacey (2009) and as discussed by Hill (1983) and Bieniawski (1988), the design process is a logical sequence of events that provides a work plan for the design programme. The six design principles for rock engineering were developed by Bieniawski $(1991,1992)$ and whilst these principles were developed specifically for rock engineering, they are applicable to any engineering design or investigation according to Stacey (2009). These principles are:

1. Clarity of design objectives and functional requirements.

2. Minimum uncertainty of geological conditions.

3. Simplicity of design components.

4. State-of-the art practice.

5. Optimisation.

6. Constructability.

Based on Bieniawski's (1991, 1992) design principles, Stacey (2009) summarised the design process into 10 sequential steps (Figure 1 ).

\section{$3 \quad$ The dewatering system design process}

The abovementioned process will form the basis of the proposed methodology for a dewatering system design process and each of the ten elements will be discussed in more detail in the following sections.

\subsection{Statement of the problem}

There are three main objectives of an effective dewatering system on any sub surface mining operation, namely to:

1. Reduce slope instability risk.

2. Reduce the impact of groundwater on mine production.

3. Reduce operational costs.

\subsubsection{Reduce slope instability risk}

Groundwater usually have a detrimental effect on slope stability and since it is the only factor that can be changed, the importance of understanding the potential impact on stability and the controls necessary to reduce the risk need to be incorporated into the slope design process. This will ensure a geotechnical design that incorporates dewatering aspects throughout the design process with the ultimate aim to design the most cost effective slopes (Read and Stacey, 2009). 

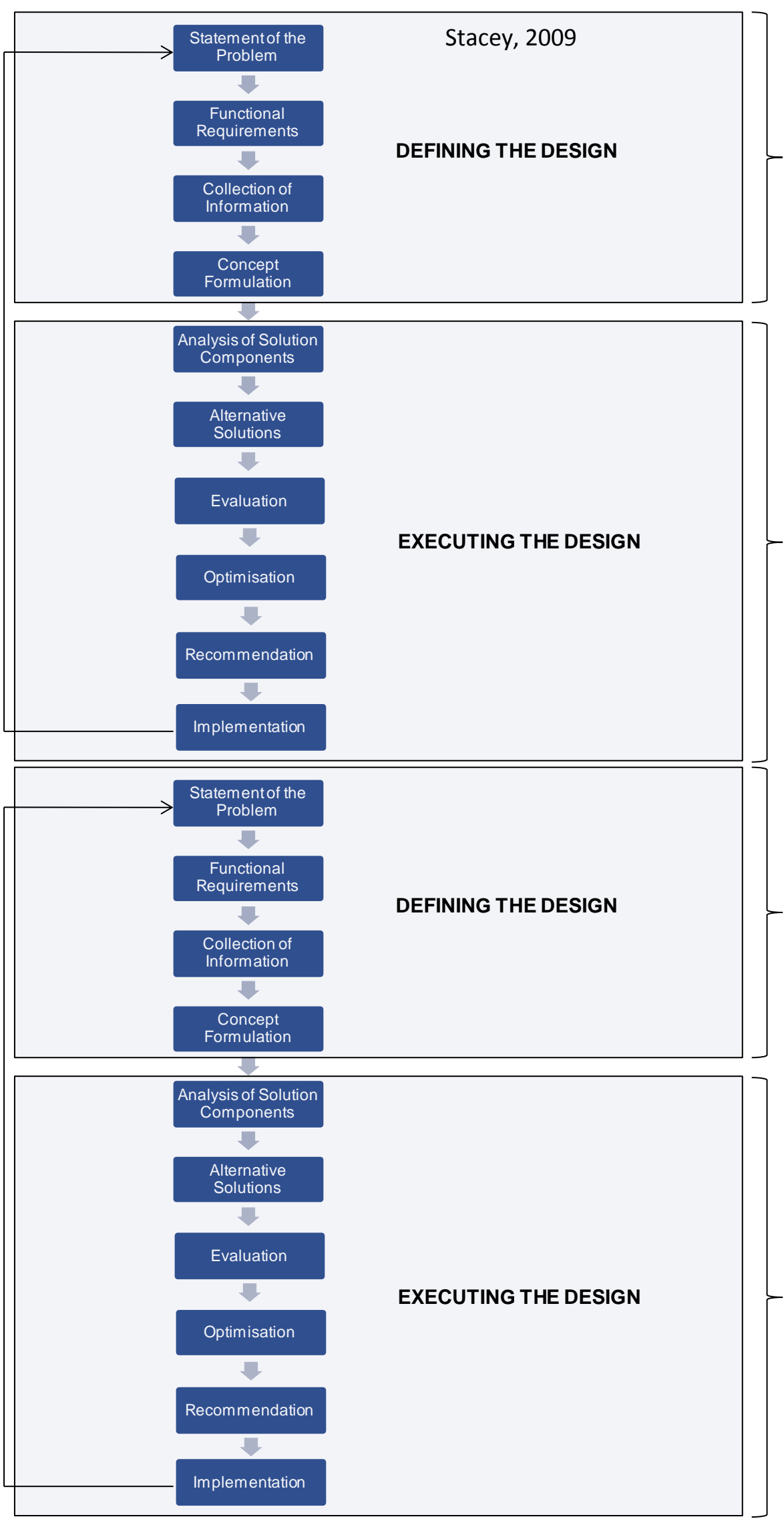

4. State of the art practice

5. Optimisation

6. Constructability

Figure 1 Engineering design steps corresponding to design principles (after Stacey, 2009) 


\subsubsection{Reduce the impact of groundwater on mine production}

The handling of material in dry conditions is more efficient, reduces safety risk and will therefore increase production rates opposed to mining in saturated conditions.

\subsubsection{Reduce operational cost}

Wet and saturated production conditions can lead to an increase in costs due to the increased wear and corrosion on equipment as well as decreasing the operating life of machinery. Haulage costs for unsaturated material is significantly less than for saturated materials and additionally, saturated conditions lead to increased drilling and blasting costs.

\subsection{Functional requirements and constraints}

The following aspects should be addressed by the dewatering design:

- The most efficient dewatering system should be designed to ensure dry mining conditions and depressurised slopes without impacting on the probability of achieving the mine plan.

- Engineering and infrastructure requirements to discharge mine water.

- Monitoring program.

- Legal compliance in terms of quality and quantity of discharged mine water.

- Understand and manage the environmental impact.

- Cost.

- Conditions after mining have ceased.

\subsection{Collection of information}

The success of a dewatering system is directly linked to a sound understanding of the geological and hydrogeological setting of the aquifer. Appropriate data levels for the different project stages throughout the project life cycle should therefore be captured to accurately perform hydrogeological site characterisation. Figure 2 provides guidelines on typical data requirements from the conceptual phase to operations.

During the early geological exploration drilling phase, any information concerning water strikes that were encountered as well as water level measurements should be captured. More detailed data can be obtained as the project progresses from geotechnical drilling, airlift testing, injection tests, packer tests and piezometers. This allows for a more detailed hydrogeological analysis than would otherwise be possible.

Rainfall and evaporation data should also be collected and captured.

A regional hydrogeological census should be performed to collect vital baseline information on water levels, quality and pumping information where available as this will assist with aquifer delineation and with the management of future environmental impacts. 


\begin{tabular}{|c|c|c|c|}
\hline $\begin{array}{l}\text { Fatal flaw analysis using } \\
\text { initial data or publicly } \\
\text { available information, } \\
\text { including: } \\
\text { (i) Ground water regime } \\
\text { likely to be encountered. } \\
\text { (ii) Possible aquifers and } \\
\text { water levels. } \\
\text { (iii) Likely porosity and } \\
\text { permeability. }\end{array}$ & $\begin{array}{l}\text { Collect appropriate } \\
\text { hydrogeological data to } \\
\text { define likely mining and } \\
\text { processing risks. } \\
\text { (i) Description of aquifers, } \\
\text { water levels, porosity, } \\
\text { permeability, pore } \\
\text { pressure and direction } \\
\text { and strength of flow. } \\
\text { (ii) Representative tests of } \\
\text { water quality } \\
\text { (iii) Determine likely impact } \\
\text { on mining } \\
\text { (iv) Develop a numerical } \\
\text { groundwater model, if } \\
\text { required. } \\
\text { (v) Acid base accounting } \\
\text { (where appropriate) }\end{array}$ & $\begin{array}{l}\text { Provide a full } \\
\text { description of the } \\
\text { groundwater } \\
\text { regime. } \\
\text { (i) As for } \\
\text { conceptual, plus: } \\
\text { (ii) More detailed } \\
\text { data for } \\
\text { increased } \\
\text { confidence in the } \\
\text { payback period. } \\
\text { (iii) Develop a } \\
\text { predictive } \\
\text { numerical } \\
\text { groundwater } \\
\text { model to } \\
\text { evaluate different } \\
\text { scenarios, if } \\
\text { required. } \\
\text { (iv) Develop a } \\
\text { groundwater } \\
\text { management } \\
\text { programme for } \\
\text { construction and } \\
\text { operation (e.g. } \\
\text { Depressurisation } \\
\text { and dewatering). }\end{array}$ & $\begin{array}{l}\text { Demonstrate an efficient } \\
\text { and effective dewatering } \\
\text { system. } \\
\text { (i) Detailed conceptual } \\
\text { geohydrological model } \\
\text { (ii) Predictive numerical } \\
\text { model } \\
\text { (iii) Effective dewatering } \\
\text { strategy for construction } \\
\text { and operation } \\
\text { (iv) Comprehensive } \\
\text { monitoring network } \\
\text { (v) Efficient groundwater } \\
\text { management plan } \\
\text { (vi) Comply to all legal and } \\
\text { environmental } \\
\text { requirements. }\end{array}$ \\
\hline
\end{tabular}

Figure 2 Hydrogeological requirements throughout the project life cycle

\subsection{Concept formulation}

The objective of a conceptual model is to assess and simplify the complex regional hydrogeological setting in natural conditions and attempts to further understand the impacts of mining. The conceptual model integrates the field parameters previously collected to produce a simplified but accurate representation of the geological and hydrogeological setting.

The conceptual model can be presented graphically, typically in cross-section or block diagram format, with supporting descriptions. An example from Sishen Mine of such a presentation of the conceptual model for a groundwater flow system is presented in Figure 3 . The key elements from a conceptual model as summarised from Middlemis (2001) are:

- The catchment framework, defining the boundaries of the study area, in terms of groundwater and surface water divides.

- The hydrogeological framework, in terms of the general structure and properties of the aquifers and the geological units making up the catchment.

- The surface water framework, the configuration of streams, lakes, wetlands, and other surface water features in the catchment.

- The hydrological framework, the key processes defining the movement of water throughout the system such as rainfall, evapo-transpiration, runoff, stream flow and groundwater flow.

- The anthropogenic framework, the human-induced factors that can influence hydrological processes in terms of water quantity and quality, such as mining. 


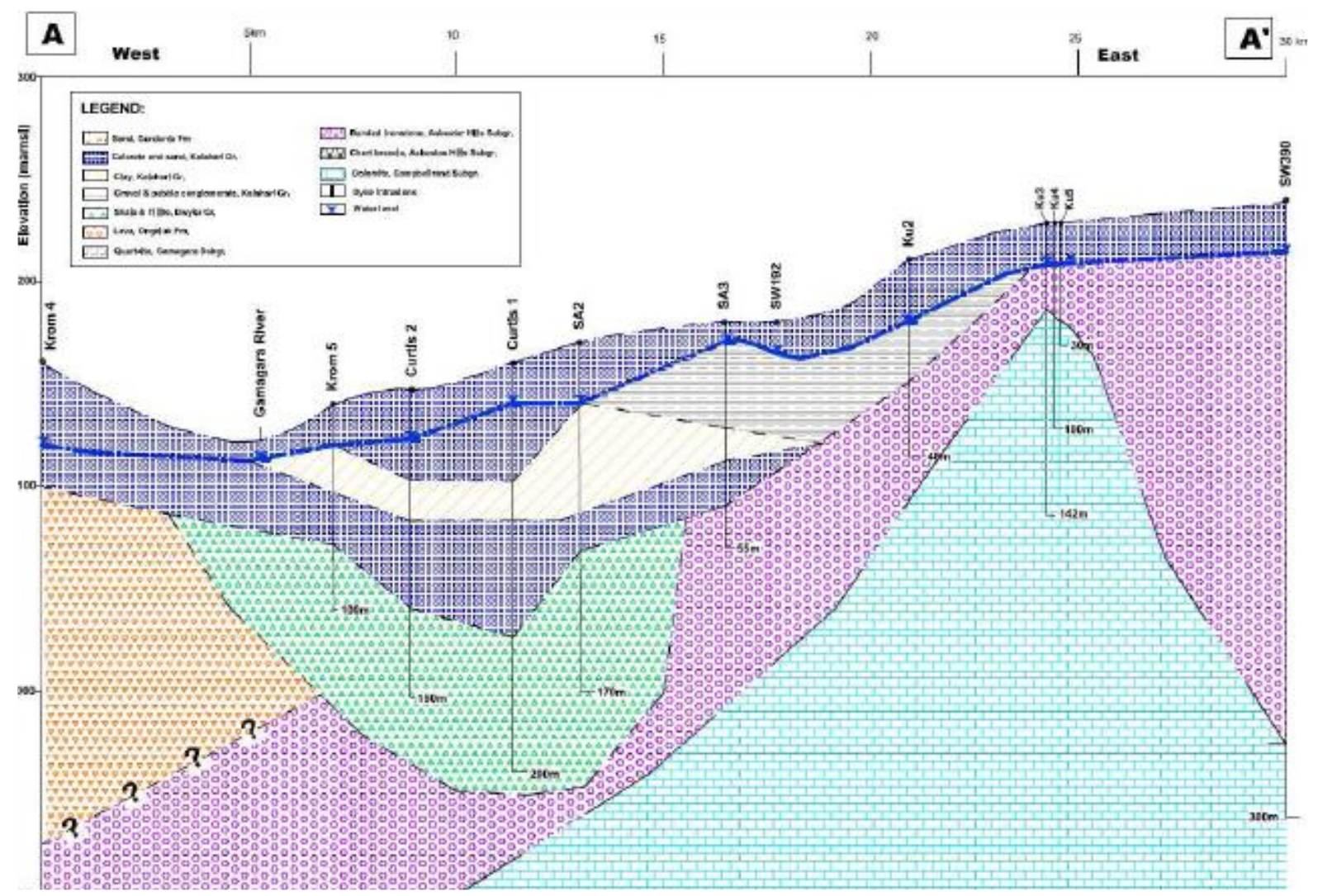

Figure 3 Example of a cross-section of conceptual model for the groundwater system of Sishen Mine (Meyer, 2009)

\subsection{Analysis of solution components and alternative solutions}

Based on the conceptual hydrogeological model, the geotechnical design and the mining plan, the requirements and methodology to be followed for the dewatering design are investigated during this phase. The complexity of the conceptual hydrogeological model will determine which analytical, numerical, empirical or observational methods can be utilised to determine the dewatering requirements.

Most commonly, a numerical model is designed to estimate the volumes of water to be managed during the expected mining period, thereby assisting in the design of an effective dewatering system and determining the extent of the impact the proposed dewatering will have on the surrounding area. This process is illustrated in Figure 4. 

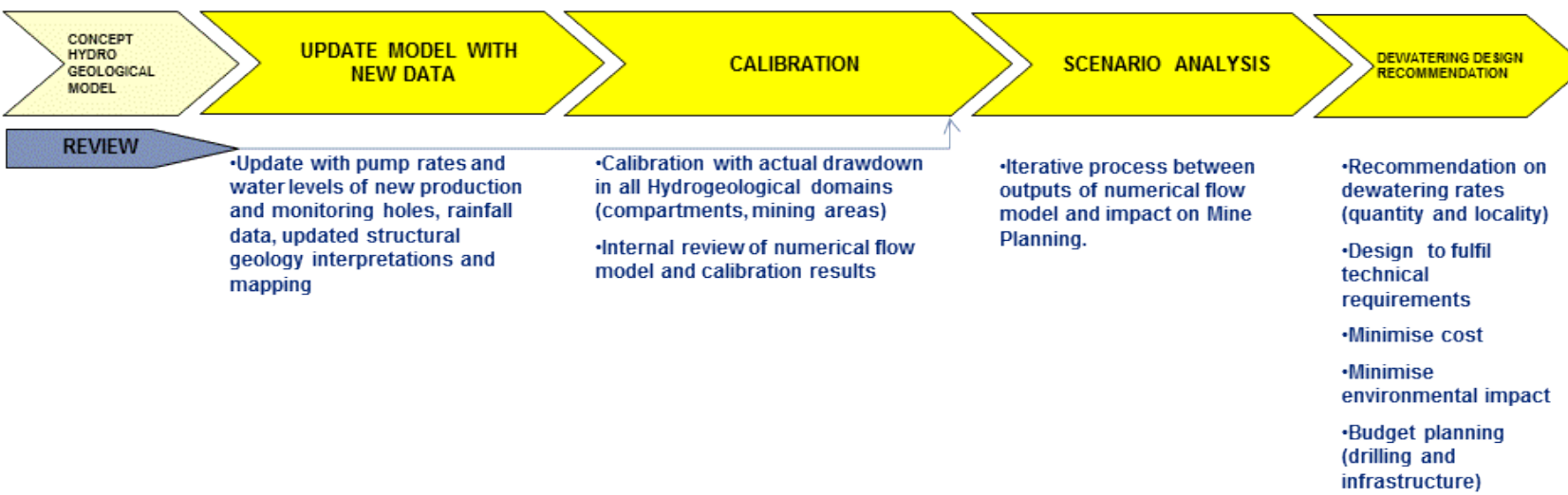

\section{Figure 4 Numerical flow modelling process}

Numerical models use approximations (e.g. finite differences or finite elements) to solve the differential equations controlling groundwater flow. For these approximations, the model domain and time is discretised. In this discretisation process, the model domain is represented by a network of grid cells or elements, and the time of the simulation is represented by time steps. Depicted in Figure 5 is an example of the numerical flow model for Sishen Mine utilising the finite element approach (Itasca, 2011) highlighting various geological features such as rock types, faults, dykes etc. considered in the model.

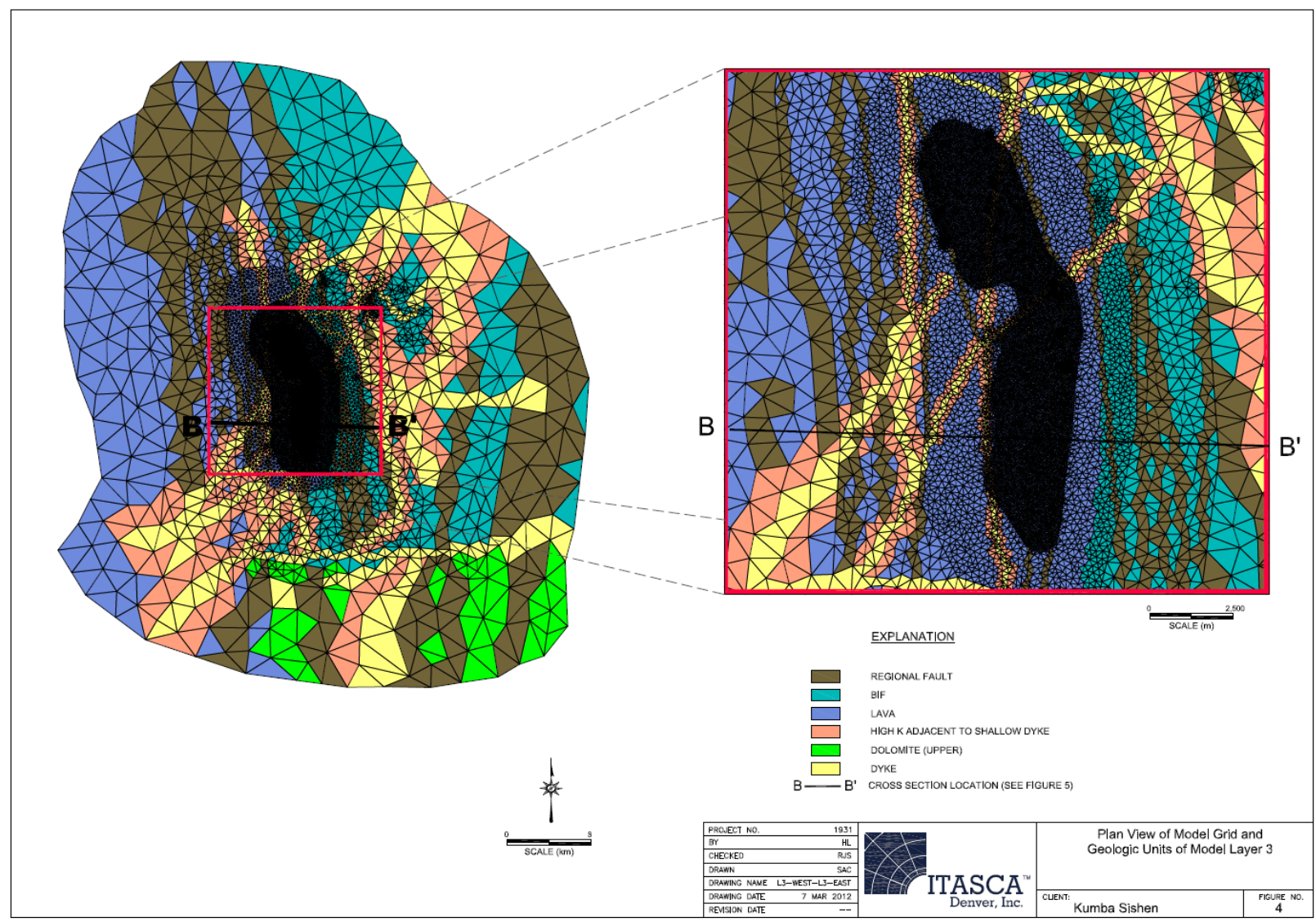

Figure 5 The Sishen model as an example of a numerical model (Itasca, 2011)

The data previously collected is incorporated into this three dimensional numerical flow model. By attempting to simulate the lateral and vertical movement of the groundwater the model will predict the 
abstraction volumes necessary to ensure dry mining conditions. The amount and quality of data available will therefore determine the accuracy of the model.

Although the predictive ability of the model is not entirely reliable, it remains a powerful tool for determining a dewatering design that will address the required aspects.

Subsequent to determining the dewatering requirements, the method of dewatering needs to be investigated. A number of methods to effectively dewater a site exist and can be classified as either removing or diverting groundwater (Morton, 1993).

To divert the water would mean to deflect the flow of the water away from the subsurface area. Different methods of diversion are:

- Grout injection and grout curtains.

- Cover drilling.

- Grout piling.

Diversion methods are more effective where groundwater flow is mainly controlled in structures or groundwater channels. The main factors to take into account when considering and applying this method would be cost involved and effectiveness of this method at greater depths.

Dewatering is the removal of groundwater at a rate that exceeds the natural recharge and thereby depleting the aquifer and lowering the water table in the process. Morton (1993) lists the following dewatering methods and which are illustrated in Figure 6:

- Dewatering wells.

- Dewatering galleries.

- Drains.

- Sumps.

- A combination of the above.

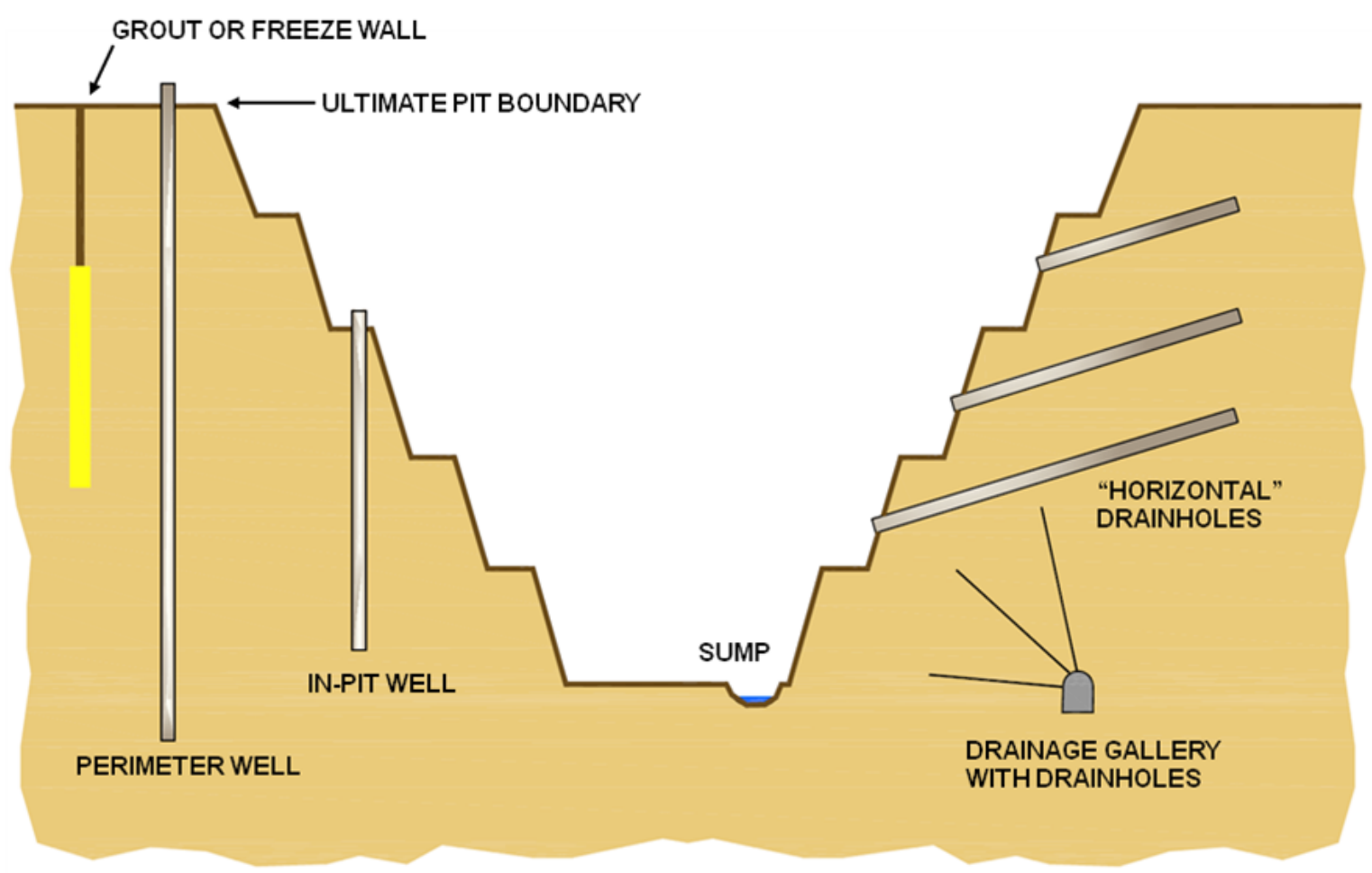

Figure 6 Different methods of pit dewatering (Itasca, 2011) 


\subsection{Evaluation and optimisation}

Once calibrated, the numerical model allows multiple dewatering scenarios (including methods) to be evaluated without having to commit any further financial expenses. An iterative process between the outputs obtained from the numerical model and the impact on the mine plan is investigated during this phase.

Ranking of the chosen alternatives by considering cost and practicality ensures an optimised design that will fulfil all technical requirements.

\subsection{Dewatering design recommendation}

Based on the results of the optimisation phase, a dewatering design is considered that has the greatest likelihood of both fulfilling the technical requirements while minimising cost and environmental impact.

The approved design is implemented during the next phase. For the purpose of this paper Sishen and Kolomela Mines will be discussed as case studies.

\subsection{Implementation of the dewatering system}

Mine dewatering at Sishen and Kolomela Mines can effectively be achieved by pumping continuously from a series of dewatering wells in and around the pit. Surface water from rainfall events is removed by the installation of mobile pumps in sumps on the mine floor and pumping the water out of the pit.

The following steps are followed in the implementation of the dewatering design.

\subsubsection{Target generation and water exploration drilling}

Target generation for dewatering wells consists of a groundwater exploration drilling programme that combines available information such as the evaluation and interpretation of geophysical data, data captured during geological exploration drilling, the geological / structural model of the site (refer to Figure 7) and the mine development plans to determine favourable drilling positions. Planning of wells are based on available data in terms of possible water bearing structures, the expected drilling conditions, the required drilling depth as well as the configuration and construction of wells.

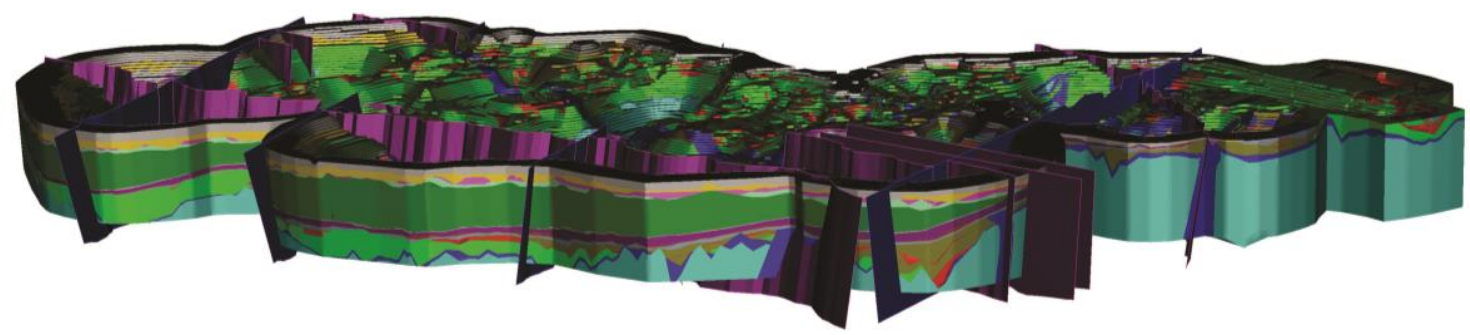

\begin{tabular}{|c|c|c|}
\hline $\begin{array}{l}\text { Model } \\
\text { Code }\end{array}$ & Lithology & Includes Logging/Geological Codes \\
\hline \multicolumn{2}{|c|}{ DIA Diabase } & DI, DIO, DLT, GAB, SDT \\
\hline cc & Calcrete & CC, FER, GRV, LIM, SLT, MDS, MUD, SD, SL, LST \\
\hline CLAY & Clay & CL, TAL, TUF \\
\hline PEB & Pebble Layer & PEB \\
\hline LAV & Lava (Weathered) & LAW \\
\hline LAW & Lava (Fresh) & LAV, AGL, DMT, SHD, TIL \\
\hline SHTU & Upper Tectonized Shale & SH, SHT \\
\hline aTz & Quartzite & QTZ, SST, VQ \\
\hline SHTL & Lower Tectonized Shale & SH, SHT \\
\hline FLS & Flagstone (Prob. Tectonized) & FLS \\
\hline (GAM) & Gamagara & KGT (CGT, CGB, GRS); SK (SH, SHA, SHC): EKG (HC, HG) \\
\hline ORE & Ore & $\mathrm{HB}, \mathrm{HD}, \mathrm{HL}, \mathrm{HM}$ \\
\hline BIF & Banded Iron Formation & BIF, BIB \\
\hline DOL & Dolomite & DOL \\
\hline
\end{tabular}

Figure 7 Structural model for Sishen Mine (Basson, 2011) 
Subsequent to a drilling target being successful and yielding a sufficient airlift yield, the well is pump tested to determine whether a large diameter $(38 \mathrm{~cm})$ production dewatering well is to be drilled.

\subsubsection{Aquifer testing}

According to Sterret (2007) a constant rate aquifer test consists of pumping a well at a specific rate for a certain period of time and recording the drawdown in both the pumping well and in nearby observation wells.

At Sishen and Kolomela Mines constant rate pumping tests are performed and recoveries analysed to determine:

- The aquifer properties (transmissivity and storativity).

- The maximum rate that can be obtained from the borehole in order to deplete the aquifer.

Generally no infrastructure exists at this stage at the borehole, as such the equipment that is used must be fully mobile and power has to be generated on site. This limits the type and size of pump that can be utilised. For a successful constant rate pumping test sufficient drawdown must be achieved during the testing period and it is therefore essential that appropriate and specialised equipment is utilised in order to perform tests which are suitable for the diameter, depth and likely yield of the wells to be tested.

\subsubsection{Pump selection and well design}

After a constant rate pumping test is performed on a water yielding exploration well, the results are analysed to determine whether it will be feasible to drill and equip a large diameter dewatering well.

Once the decision is made to drill a production well, the pump selection process starts with matching the best efficiency point of available pumps with the maximum yield of the aquifer determined from pump testing. The following aspects are normally considered for pump selection and are also applied at Sishen and Kolomela Mines include (Sterret, 2007):

- The required flow.

- Head capacity.

- Pump efficiency.

- Pump power output.

- Net positive suction head required.

Other less frequently examined aspects of pump selection include (Sterret, 2007):

- Minimum pump submergence.

- Pump diameter.

- Pump rotational speed.

- Hydraulic thrust.

- Mechanical balance to prevent vibration.

At Sishen and Kolomela the deepest possible fracture / water bearing zones are targeted and the installation of perforated casing is planned around the depth of water bearing zones intersected in the exploration hole.

The correct design and construction of dewatering wells are therefore essential to achieve the following outcomes:

- Optimum pumping rates and maximum drawdown. 
- Maximum operating life of wells.

- Minimised maintenance costs.

\subsubsection{Dewatering well drilling}

The production dewatering well is drilled as close as possible to the exploration hole. The position of these wells is crucial and has to be communicated and integrated into the mining plans. Wells should ideally be drilled at positions where the impact from dewatering will be the most effective but also taking into account where the well can remain undisturbed from mining activities for as long as possible.

Two drilling methods have been applied at Sishen and Kolomela Mines depending on drilling conditions:

- Air percussion drilling (including utilising wing bits and casing advance systems in difficult ground).

- Mud rotational drilling.

Mud rotational drilling is typically utilised in conditions where air loss is experienced due to the intersection of fault zones and cavities in the geological profile.

The drilling programme and pump testing of the wells at Sishen and Kolomela Mines are performed by contractors who have specialised equipment and the expertise to execute the required functions and meet the design criteria.

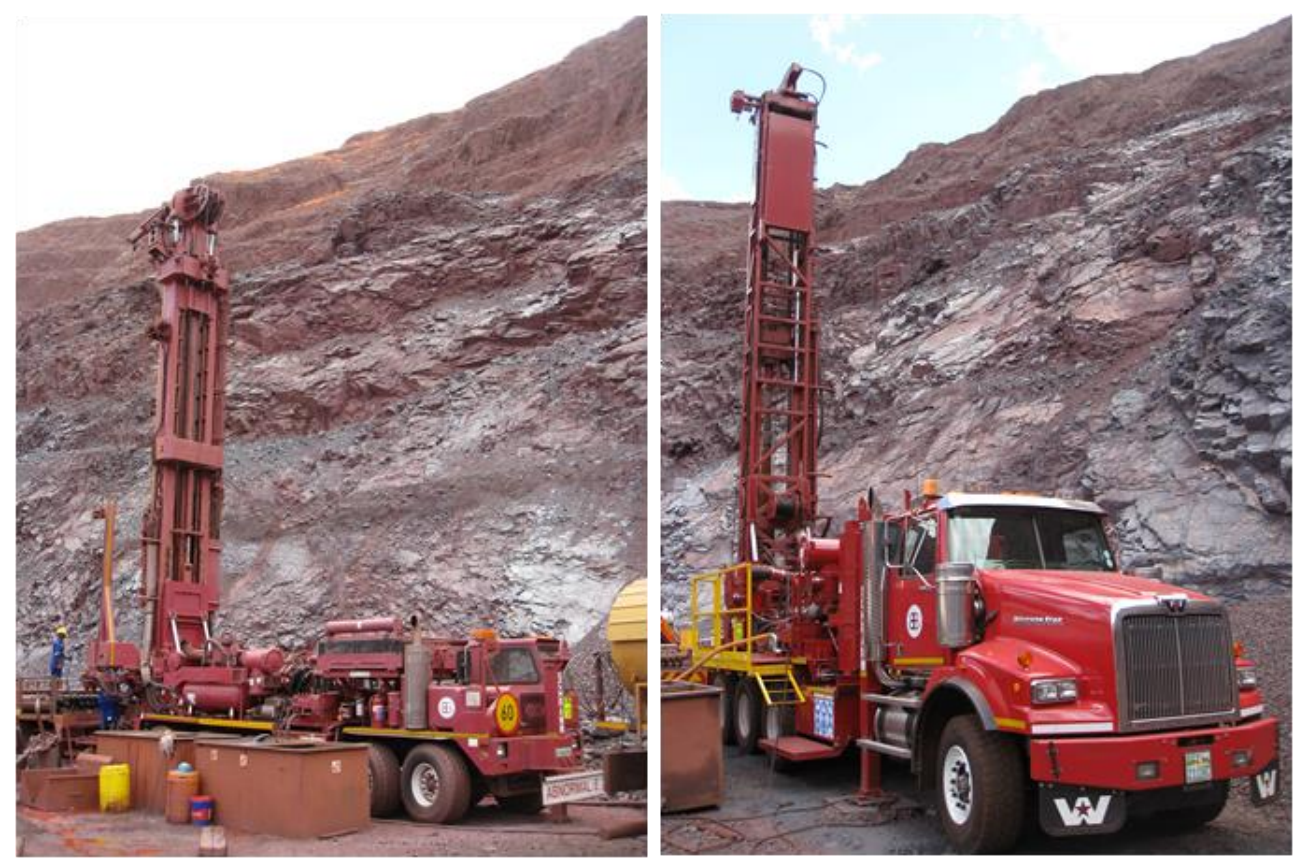

Figure 8 Schramm drill rigs utilised at Sishen Mine

The technical capacity and suitability of drilling equipment as illustrated in Figure 8 , skill and experience of the drill operators, safety compliance and cost are the key aspects determining the selection of a successful contractor. Sishen and Kolomela Mines strive to advance healthy partnerships with dewatering contractors to ensure the safe implementation of the mines' dewatering programs. Production well planning discussions are held to ensure efficient well construction as well as frequent safety inspections and meetings to ensure compliance with all Anglo American site and corporate safety regulations and procedures.

\subsubsection{Equipping of boreholes and dewatering infrastructure}

Collaboration with personnel from a wide range of disciplines (mechanical, electrical, civil, geotechnical engineering, mine planning and construction) are required to ensure dewatering wells are equipped with 
the correct submersible pumps and to ensure that dewatering infrastructure meets the requirements of discharging groundwater to different discharge points. A dewatering forum was initiated at Sishen Mine with a champion from engineering maintenance assisting the hydrogeologist in the Geotechnical Engineering department to oversee the efficient management of existing infrastructure as well as the construction of new pipelines and equipping of new wells to meet future needs.

\subsection{Monitoring}

In order to manage an effective mine dewatering system, comply with regulatory requirements and to understand the environmental impact of regional drawdown, a comprehensive and accurate monitoring network around the mine and surrounding areas is critical. Deviations or anomalies in the monitoring data from the conceptual understanding or modelled dewatering response should automatically trigger a revision of the design process.

Flow meters, time meters and pressure meters are installed at all production wells with a link to a central control system to enable the effective management of the dewatering system and ensure acceptable maintenance availability as well as to ultimately optimise the integrated system in terms of hydraulic constraints.

Sishen and Kolomela Mines' dewatering systems are supplemented by comprehensive groundwater monitoring programmes illustrated in Figures 9 and 10.

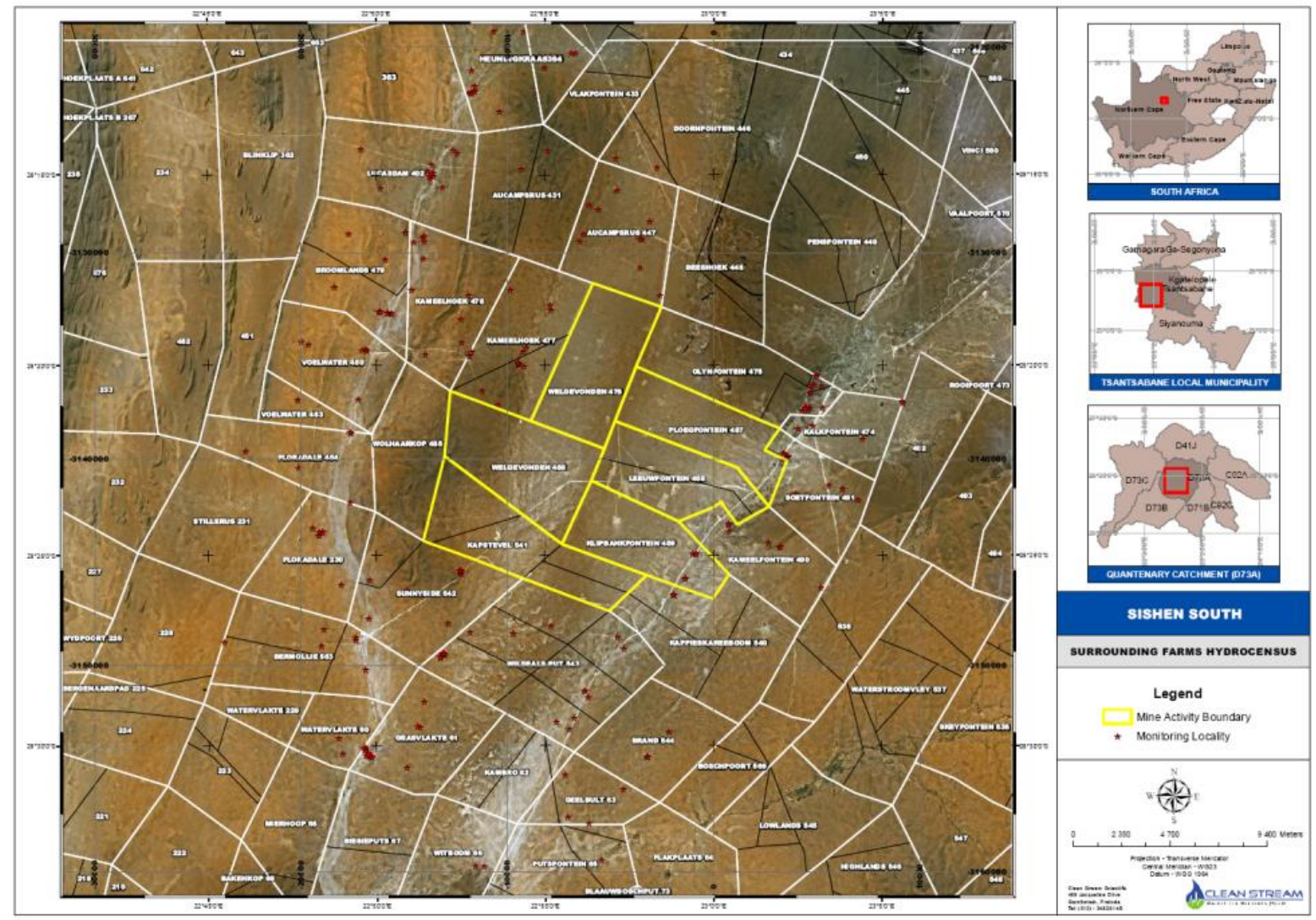

Figure 9 Regional monitoring networks at Kolomela Mine

The following parameters are monitored:

- Pumping rates (volume over time).

- Dynamic water levels in the pumping wells.

- Groundwater levels of wells in the pit and groundwater levels in the regional aquifer influenced by mine dewatering. 
- Volumes of groundwater discharged to different users within the mine and outside the mine.

- Rainfall data.

- Quality of groundwater collected in the mine.

- Quality of water discharged from the mine.

- Volume and quality of surface water discharged from the mine.

- The establishment and development of an effective monitoring system through sound data acquisition and data management principles enables an operation to minimise environmental impact whilst fulfilling all legal requirements. Data management, legal compliance and environmental impact management with a sound monitoring program as the basis will be briefly discussed in the following section. 


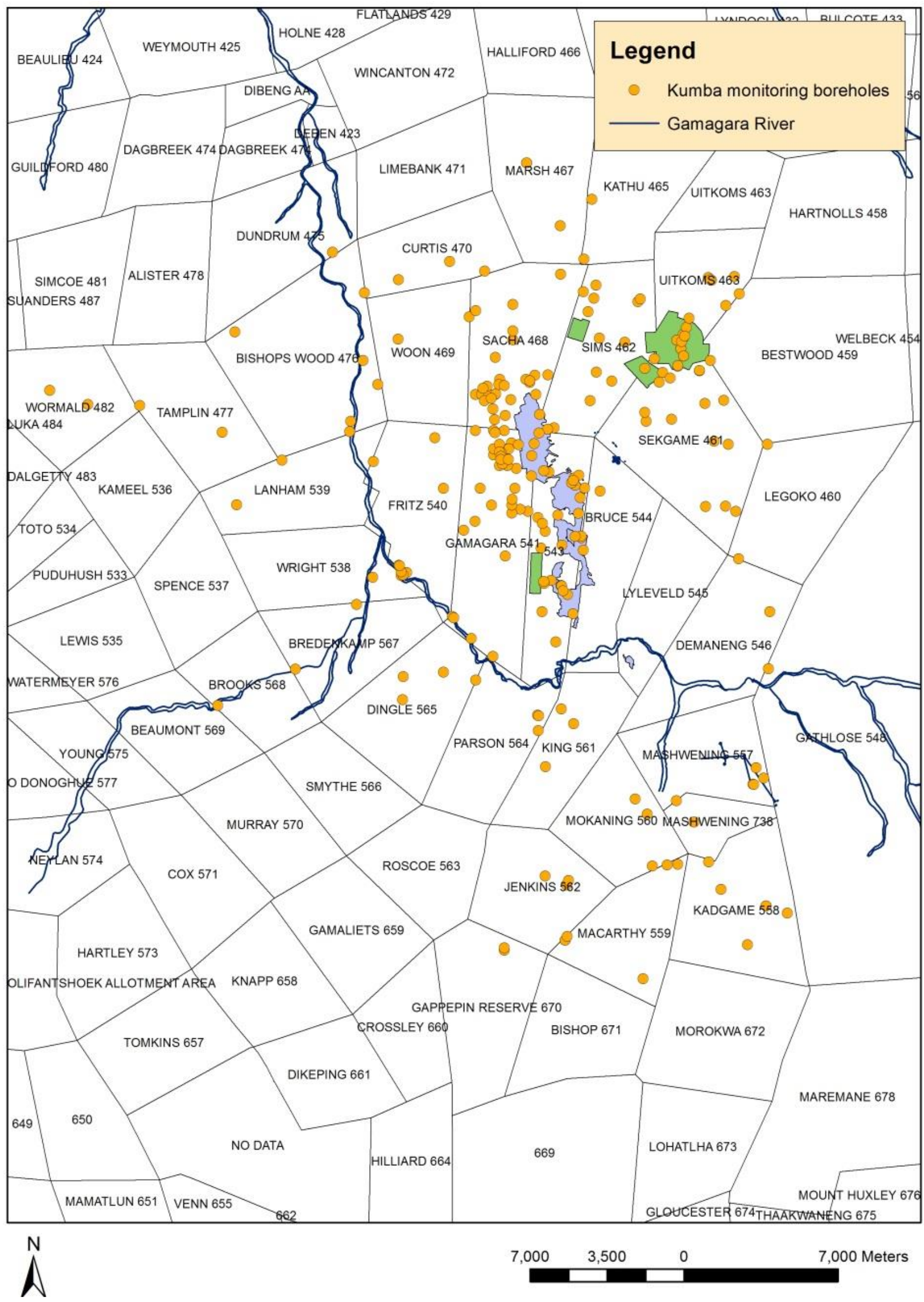

Figure 10 Regional monitoring networks at Shishen Mine 


\subsubsection{Dewatering information system}

Managing large volumes of data from multiple well locations and data points at a site like Sishen Mine can be challenging. All data collected from monitoring and drilling programmes are captured in a Water Information System database specifically developed to suit the needs of Kumba Iron Ore's operations (refer to Figure 11).

Relevant information is extracted from the database for management reporting as well as to fulfil requirements for reporting to relevant regulatory authorities.

Subsequently, the numerical models of the mines are systematically updated with all new information captured in the Water Information System with the aim of improving the accuracy of future dewatering predictions as well as possible environmental impacts.

The monitoring program is continuously evaluated with the purpose of identifying areas of uncertainty in order to expand the monitoring network and include additional monitoring data points.

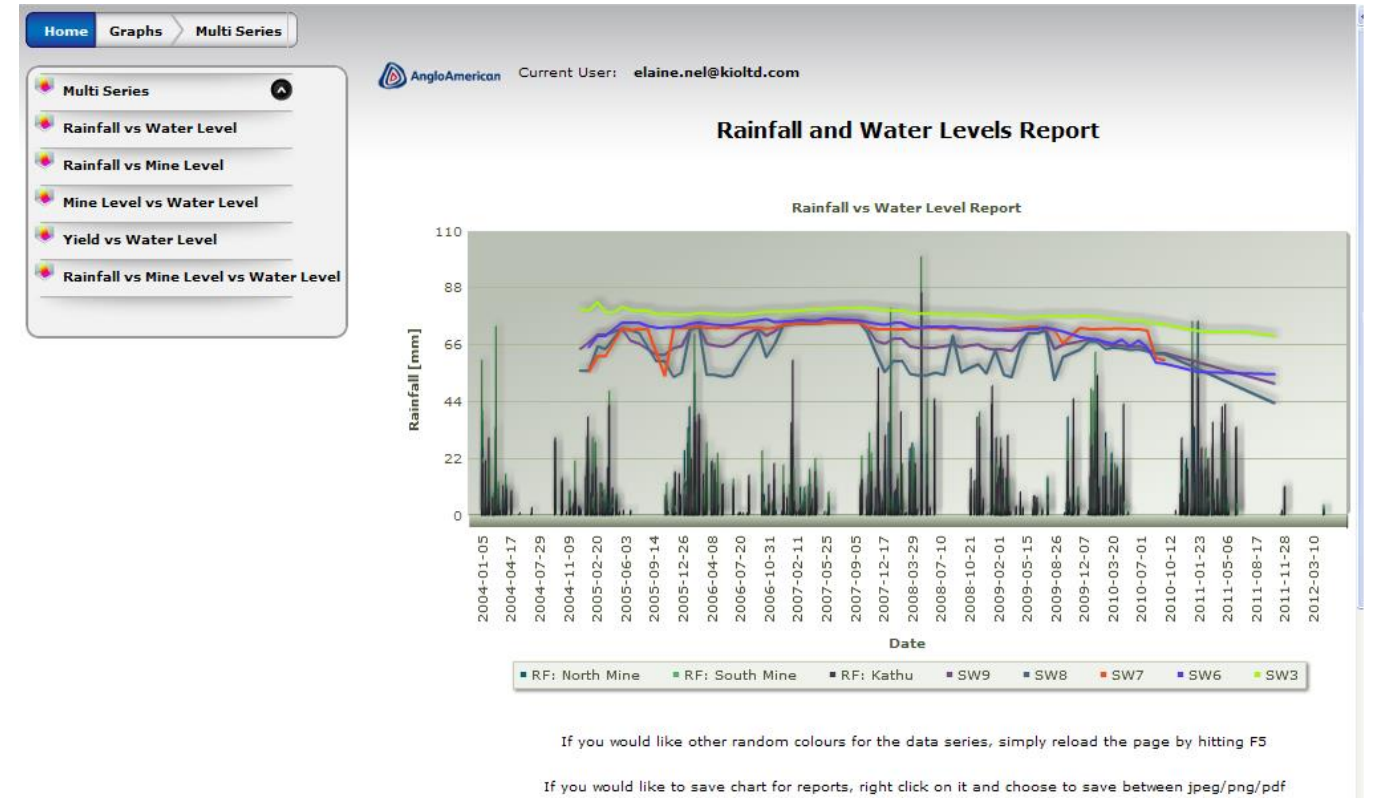

Figure 11 Water information system and interface

\subsubsection{Legal compliance}

Fulfilment of all environmental and water legal requirements is fundamental for Kumba Iron Ore operations and aligned with Anglo American values to be a responsible mining company. Reporting to the relevant authorities is made on required intervals. Licence agreements are evaluated periodically and amendments are made if necessary to ensure that dewatering and discharge rates are within agreed limits.

\subsubsection{Environmental impact}

The following have been implemented at operations in order to manage the environmental impact caused by dewatering and can be regarded as examples of dewatering impact management actions:

- The existing monitoring network is expanded by drilling of additional wells in areas of uncertainty.

- A formal process was established to effectively deal with all complaints once received and logged.

- An independent hydrogeologist was appointed to investigate all water related issues from land owners on a continuous basis utilising the extensive database available. 
- Supply of water to impacted land owners via a pipeline; this is managed on a daily basis and in certain cases trucked water was supplied as an interim measure. A number of boreholes outside the mine were also drilled and equipped specifically to supply water to affected land owners.

- Sishen Mine has appointed a senior employee from the mine to engage with affected land owners and to coordinate above mentioned actions.

- Quarterly Environmental Forum meetings are held, which is the official liaison forum between the mine and the farming community. This forum is facilitated by an independent facilitator, as suggested by the landowners. The Water User Association, Department of Water Affairs (DWA) and other stakeholders also participate in this forum.

- All groundwater related monitoring data is reported to DWA as indicated in the water licence.

- A data exchange agreement was negotiated with neighbouring mines in order to ensure all data is available for improved understanding of the hydrogeological environment. This in turn will facilitate responsible management of the dewatering impact.

\section{$4 \quad$ Conclusions}

The importance of water and its associated environmental impact due to mining activities are of critical importance for all operations and projects. In future it will most probably be one of the key drivers determining if a project develops into the implementation stage or not. Early stage project front end loading of hydrogeological parameters and associated environmental aspects is vital to ensure an effective and efficient dewatering system.

Therefore, in order to facilitate this outcome, a structured approach according to engineering design principles is suggested for the design and implementation of mine dewatering systems (Figure 12 overleaf).

\section{Acknowledgement}

The authors thank Anglo American Kumba Iron Ore for the opportunity to present this paper.

\section{References}

Basson, I. (2011) Sishen Mine Structural Model update, Kumba Iron Ore internal document.

Bieniawski, Z.T. (1988) Towards a creative design process in mining, Mining Engineering, Vol. 40, pp. 1040-1044.

Bieniawski, Z.T. (1991) In search of a design methodology for rock mechanics, Rock Mechanics as a Multidisciplinary Science, in Proceedings 32nd US Symposium on Rock Mechanics, J-C. Roegiers (ed), 10-12 July 1991, Norman, USA, Balkema, pp. 1027-1036.

Bieniawski, Z.T. (1992) Invited Paper: Principals of engineering design for rock mechanics, in Proceedings 33rd US Symposium on Rock Mechanics, J.R. Tillerson and W.R. Wawersik (eds), 3-5 June 1992, New Mexico, USA, Balkema, pp. 1031-1040.

Hill, P.H. (1983) Techniques in teaching creative engineering design, in Proceedings ASEE Annual Conference, 19-23 June 1983, Henrietta, USA, American Society for Engineering Education, New York.

Itasca (2011) Numerical modelling of the Sishen acquifer, Kumba Iron Ore internal document.

Meyer, R. (2009) Sishen Mine conceptual geohydrological model, Kumba Iron Ore internal document.

Middlemis, H. (2001) Groundwater flow modelling guideline, Murray Darling Basin Commission.

Morton, K.L. (1993) A Phased Approach to Mine Dewatering, Mine Water and the Environment, Vol. 12, Annual Issue, pp. 27-34.

Read, J. and Stacey, P. (2009) Guidelines for Open Pit Slope Design, CSIRO Publishing.

Stacey, T.R. (2009) Design-a strategic issue, The Southern African Institute of Mining and Metallurgy, SA ISSN 0038-223X/3.00 + 0.00 .

Sterret, R.J. (2007) Groundwater and Wells, Third Edition, A comprehensive guide for the design, installation, and maintenance of a water well, Johnson screens, A Weatherford Company. 


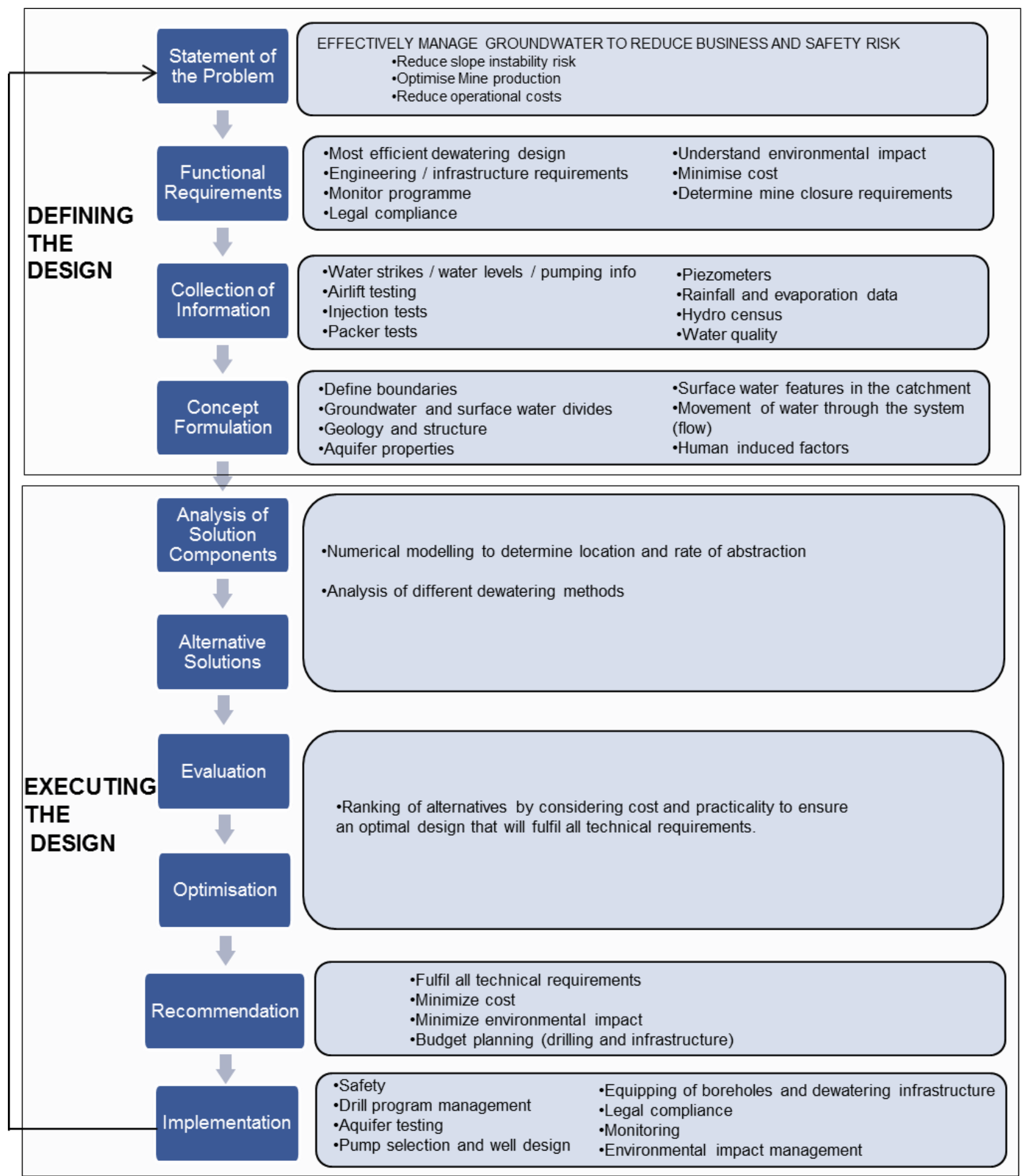

Figure 12 A summary of the design process for mine dewatering according to engineering design principles 